\title{
Le langage des larmes aux siècles classiques, sous la direction d'Adélaïde Cron et Cécile Lignereux
}

\section{Benedetta Papasogli}

\section{(2) OpenEdition}

\section{Journals}

\section{Edizione digitale}

URL: http://journals.openedition.org/studifrancesi/8904

DOI: 10.4000 /studifrancesi.8904

ISSN: 2421-5856

\section{Editore}

Rosenberg \& Sellier

\section{Edizione cartacea}

Data di pubblicazione: 1 octobre 2008

Paginazione: 451

ISSN: 0039-2944

\section{Notizia bibliografica digitale}

Benedetta Papasogli, «Le langage des larmes aux siècles classiques, sous la direction d'Adélaïde Cron et Cécile LignereuX», Studi Francesi [Online], 155 (LII | II) | 2008, online dal 30 novembre 2015, consultato il 13 janvier 2021. URL: http://journals.openedition.org/studifrancesi/8904 ; DOI: https://doi.org/

10.4000/studifrancesi.8904

Questo documento è stato generato automaticamente il 13 janvier 2021.

\section{cc) (†) $\ominus$}

Studi Francesi è distribuita con Licenza Creative Commons Attribuzione - Non commerciale - Non opere derivate 4.0 Internazionale. 


\title{
Le langage des larmes aux siècles classiques, sous la direction d'Adélaïde Cron et Cécile Lignereux
}

\author{
Benedetta Papasogli
}

\section{NOTIZIA}

Le langage des larmes aux siècles classiques, sous la direction d'Adélaïde CRON et Cécile LIGNEREUX, «Littératures classiques», n. 62, 2007, pp. 274.

1 L'originalità di questo bel volume di «Littératures classiques» è segnalata già nel titolo: non tanto per l'ossimoro (apparente) fra linguaggio, che presuppone in senso proprio la doppia articolazione, e lacrime, che rinvia alla sfera dell'emozione e dei muti segni corporei; quanto per l'ambizioso disegno di trattare i secoli classici, XVII e XVIII, come un'unità, andando oltre lo stato degli studi attuali sulle lacrime o sulla semiotica delle passioni che di solito separano accuratamente il classicismo secentesco dall'età delle Lumières e della "sensibilité" (lo dimostra anche la breve bibliografia annessa all'introduzione delle due curatrici, De la lisibilité des larmes, pp. 5-20). Da questa scommessa iniziale deriva la struttura del volume: essa non si basa su un ordine cronologico, che riproporrebbe una giustapposizione anziché una serrata dialettica fra i due secoli tanto dissimili eppure uniti, lo sappiamo, da una transizione infinitamente complessa. In realtà le cinque parti del libro esplorano tutte quella transizione, sotto forme diverse: la prima, «La spiritualité des larmes», con contributi di Aurélien HupÉ (De la chaire à l'amphithéatre: les larmes dans la poétique de la prédication, pp. 23-35), di claire FOURQUet ( $L a$ 'voix des pleurs' dans la mise en français des Psaumes, pp. 37-49) e Frédéric MIQUEL (La sécularisation des larmes mystiques au début du xviiie siècle, pp. 51-63), tratta di quella che l'introduzione chiama, un po' rudemente, la «confisca» delle lacrime da parte della spiritualità cattolica, ovvero la valorizzazione del pianto nell'eloquenza sacra, nella preghiera di origine biblica, nella mistica, giungendo all'ipotesi che la 
controversia del puro amore provochi un prosciugamento delle lacrime mistiche e la loro secolarizzazione nella sensibilità settecentesca: ci sarebbe a questo proposito da riflettere ancora sul misterioso dualismo di un Fénelon che riserba le lacrime alla tenerezza del Télémaque, e educa invece le anime all'assenza di gusti sensibili nel paesaggio secco e desertico del puro amore.

2 La seconda parte, «L'intimité des larmes», attraverso alcuni casi esemplari di scrittura alla prima persona - in M. BREST, Les larmes des religieuses captives de Port-Royal: chute et rédemption, pp. 67-77; C. LIGNEREUX, L'inscription des larmes dans les lettres de Mme de Sévigné, pp. 79-91; A. CRON, Larmes et identité féminine dans l'écriture mémorialiste, pp. 93-105 - comincia ad esplorare il potere delle lacrime nel tessuto di un discorso apologetico e persuasivo e per la costruzione nonché l'ostensione di una identità personale, in questo caso femminile, rendendo esplicito il valore di una rima privilegiata: larmes/armes/charmes. Siamo, con la terza parte («La fiction des larmes») totalmente all'interno del genere narrativo: da Mme de La Fayette (CHR. BARBILLON, La représentation des larmes dans l'oeuvre fictionnelle de Mme de Lafayette, pp. 109-121) a Mme Riccoboni (A. COUDREUSE, Pleurer en bref: le pathétique dans l'«Histoire du marquis de Cressy", pp. 149-156), da Manon a Marianne (FL. CHAPIRO, Du corps au coeur: la fonction morale du pathétique dans "Manon Lescaut", pp. 123-133, e A. ORTHOLLAND-BRAHMIA, Les larmes de Marianne, pp. 135-147), nella mobilità del ruolo diegetico delle lacrime assistiamo al trionfo di una categoria estetica, il patetico, destinata a rivoluzionare profondamente tanto le poetiche narrative e drammatiche quanto la psicologia e la morale dell'età classica.

3 È ormai il momento della messa in scena delle lacrime; la quarta parte, «Le spectacle des larmes», comprende tre studi sul teatro: una tragedia minore testimonia, poco dopo i capolavori raciniani, l'evoluzione del gusto (N. DION, Le tissé dramaturgique des larmes. "Pénélope" de l'abbé Genest, pp. 159-171), l'opéra del Settecento sfrutta abilmente non solo la retorica del pianto ma le possibilità della musica o del canto nel mimare e sublimare i segni dell'emozione (B. PINTIAUX, Rhétorique et fonction du langage des larmes dans l'opéra français $d u$ xviii siècle, pp. 173-187, e M. LAFOUGE, Le charme des larmes: l'opéra français à l'épreuve du pathétique, pp. 189-202). E ancora sul teatro, ma, più ampiamente, sulla dimensione sociale e pubblica delle lacrime, s'imposta la quinta parte del volume - «La socialité des larmes» - con quattro contributi le cui tematiche appaiono strettamente intrecciate e correlate, anche a rischio di qualche ripetizione: H. MERLIN-KAJMAN in Les larmes au xvii 'iècle: entre pathos' et 'logos', féminin et masculin, public et privé (pp. 205-221) avvia l'ampio movimento finale, ricapitolativo della raccolta; E. HÉNIN analizza finemente la trasformazione dell'idea di catarsi sotto la pressione della nuova estetica del patetico (Le plaisir des larmes, ou l'invention d'une 'catharsis' galante, pp. 223-243); D. ROCHE, partendo dall'inquieta domanda di La Bruyère sulla differente portata sociale del riso e delle lacrime, affronta la questione del pianto a teatro sotto il profilo di un'estetica della ricezione (Le partage des larmes: spectateur et tragédie au xviie siècle, pp. 245-257), e ugualmente su problemi di ricezione insiste S. MARCHAND applicando agli effetti patetici la nozione barthesiana di "mitologia" (Mythologies de l'effet pathétique au xviiie siècle, pp. 259-271).

4 La nostra rapidissima rassegna lascia trasparire alcune linee di forza che, fondandosi su acquisizioni anche recenti della critica, contribuiscono a orientare diversamente la tradizione dello studio letterario del pianto. Rimane sullo sfondo la vasta inchiesta sulla 
simbolica di sentimenti e sull'origine del pianto, che già Cureau de la Chambre dichiarava misteriosa, insieme corporea, affettiva e spirituale. Il "linguaggio" delle lacrime si dispiega qui piuttosto nella sua dimensione retorica ed estetica, inquadrandosi originalmente nello statuto dei diversi generi letterari e, infine, dalla parte del lettore e del pubblico: quest'ultimo, delicato passaggio permette di cogliere l'importanza di un'estetica delle lacrime, come momento di una intimità oggettivata $\mathrm{e}$ condivisa, per l'elaborazione di una coscienza di sé, che non ha date precise se non appunto - la complessa transizione fra XVII e XVIII secolo. 